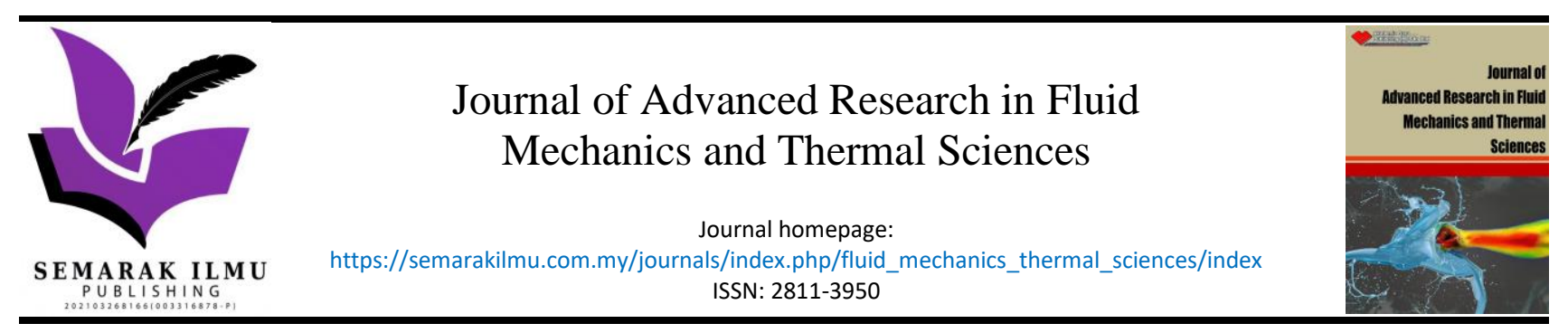

\title{
Land Clearing, Preparation and Drone Monitoring using Red-Green-Blue (RGB) and Thermal Imagery for Smart Durian Orchard Management Project
}

\author{
Ahmad Anas Yusof ${ }^{1,}{ }^{*}$, Mohd Khairi Mohamed Nor ${ }^{1}$, Nur Latif Azyze Mohd Shaari Azyze ${ }^{1}$, Anuar \\ Mohamed Kassim ${ }^{1}$, Shamsul Anuar Shamsudin ${ }^{2}$, Hamdan Sulaiman ${ }^{3}$, Mohd Aswad Hanafi ${ }^{4}$ \\ Faculty of Electrical Engineering, Universiti Teknikal Malaysia Melaka, 76100 Durian Tunggal, Melaka, Malaysia \\ Faculty of Mechanical Engineering, Universiti Teknikal Malaysia Melaka, 76100 Durian Tunggal, Melaka, Malaysia \\ 3 Faculty of Plantation and Agrotechnology (FPA), Universiti Teknologi MARA Kampus Jasin, 77300 Merlimau, Melaka, Malaysia \\ 4 Halydin Solutions. L1-S039, KIP Mart Melaka, Jalan Tun Fatimah, 75350 Melaka, Malaysia
}

\section{ARTICLE INFO}

\section{Article history:}

Received 25 July 2021

Received in revised form 3 December 2021

Accepted 7 December 2021

Available online 20 January 2022

\section{ABSTRACT}

Malaysia's agricultural activity is progressing toward the use of precision agriculture and Internet of Things (IOT) technology as the country moves forward with the adoption of Industrial Revolution 4.0. As a result, a novel approach based on spatial and thermal analysis is proposed and presented, along with a low-cost thermal and photogrammetric modelling workflow. As a result, the purpose of this project is to monitor durian orchards using drones equipped with thermal and red-green-blue (RGB) digital cameras. Thermal maps are presented to demonstrate the relationship between vegetation and soil temperature, and digital imagery from an early stage of preparation in the orchard is analysed for overall management system improvement. The findings indicate that the uneven ground surface of the orchard may have an effect on the irrigation system and crop yield production. Thermal imaging also reveals variations in soil temperature that are related to soil humidity. A well-managed orchard is essential for ensuring that the crop grows in a healthy state. The data acquisition and processing part of this workflow are being tested in Alor Gajah Smart Durian Orchard Management Project, Melaka, Malaysia.
Drones; Precision Agriculture;

Photogrammetry; Thermal Imagery

\section{Introduction}

Smart farming is a new concept that refers to the management of farms using technologies such as Internet of Things (IOT), robotics, drones, and artificial intelligence (Al) to increase the quantity and quality of products while optimizing the amount of human labor required for production. The Internet of Things (IOT) in smart farming technology refers to the concept of connected smart machines and sensors installed on farms to make farming processes data-driven and data-enabled. Simultaneously, drones or unmanned aerial vehicles (UAVs) can be integrated for monitoring and analysis in addition to crop spraying and planting from the air. In general, unmanned aerial vehicles

\footnotetext{
* Corresponding author.

E-mail address: anas@utem.edu.my

https://doi.org/10.37934/arfmts.91.1.115128
} 
have been used extensively in precision agriculture. In Malaysia, there are an increase trends of using agriculture drones in various places. Durian plantation management and rice crop monitoring using unmanned helicopter, multirotor UAV and RGB digital camera at various stages of plant growth have been extensively researched and applied. There have been a lot of studies on the use of a new type of a low-weight unmanned aerial vehicle (UAV) imaging system in the precision agriculture. Drones from various manufacturers, mostly from China (DJI) and France (Parrot) are used, which are relatively inexpensive and can be easily operated even by a novice pilot. The use of drone technology can provide farmers with information on plant health, counting and height measurement. The information can also be used in yield prediction, soil and drainage mapping and even stockpile measurements, among other things. These agricultural drones can be equipped with RGB, multispectral or thermal cameras to capture the traditional red, green blue values, near infrared and red-edge spectrum values, which is used to process and analyze vegetative indexes such as Normalized Difference Vegetation Index or NDVI maps. Typical RGB images from the field can also be stitched together using photogrammetric methods to create orthophotos, and integrated with the Geographic Information System (GIS) for spatial data collection, management and analysis [1-15].

Thermal imaging has the potential to be used in many agricultural operations, including assessing seedling viability, estimating soil water status, predicting crop water stress, planning irrigation, determining disease and pathogen affected plants, evaluating fruit yield, and assessing crop maturity [16-19].

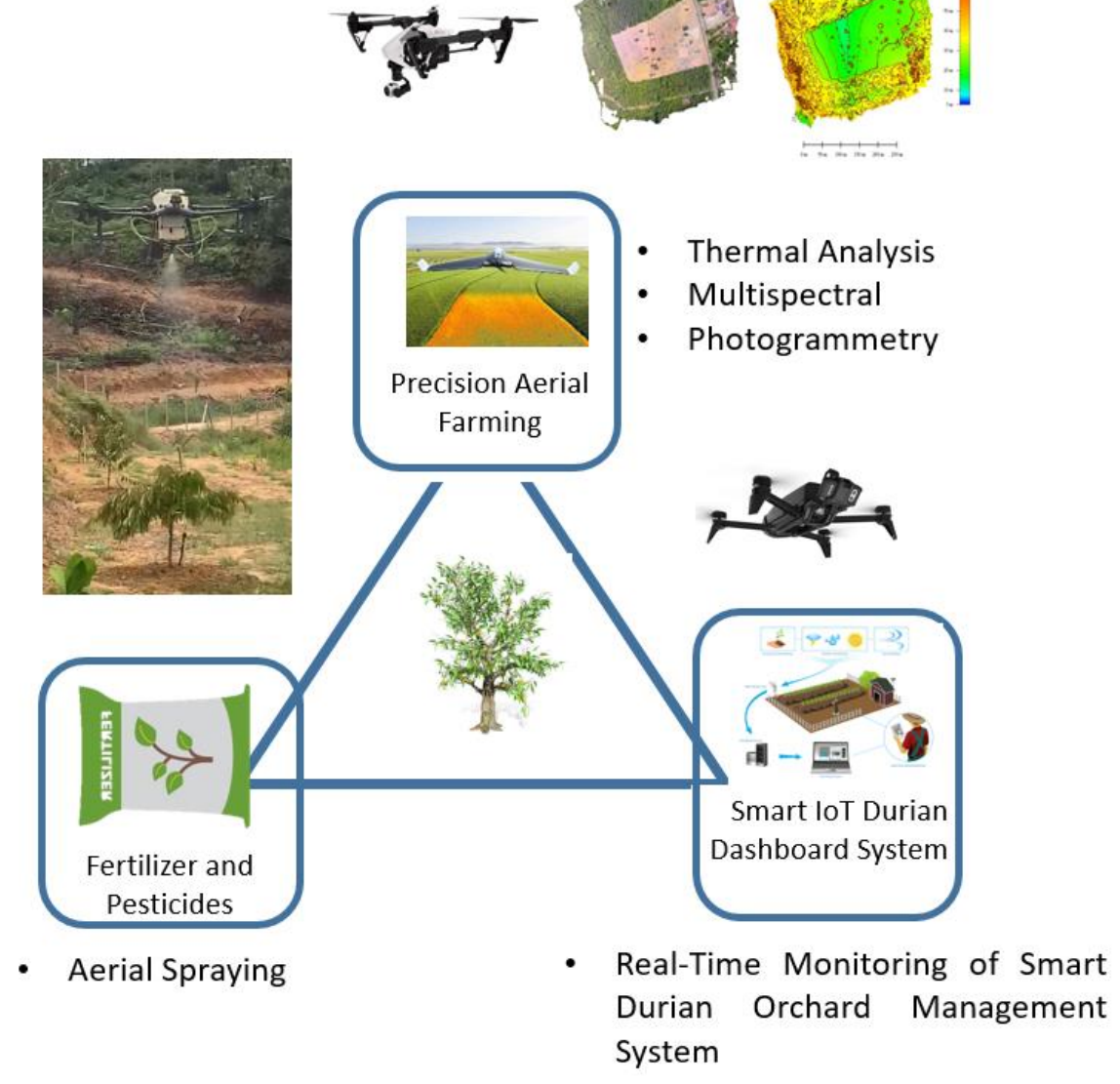

Fig. 1. Three stages of Smart Durian Orchard Management

In this project, smart farming technology in a five acres plot of durian orchard in Alor Gajah is selected to be managed at three different stages, as shown in Figure 1. The objectives of the first 
stage are to develop and incorporate a systemic drone system that can be used in as part of an effective approach to sustainable agricultural management, allowing agronomists, agricultural engineers, and farmers to help streamline their operations while gaining effective insights into their crops through robust data analytics. This comprises high-resolution photos and information technology. This is followed by the development of a smart irrigation and fertilizer control system based on soil moisture, soil $\mathrm{pH}$ and environment humidity. To assess the system's performance, research is currently being conducted by collecting data from the air and on the ground. The second stage involves the development of an Internet of Thing (IOT) platform for agricultural data collection. An interactive dashboard system for precision agriculture monitoring and data exchange will be integrated and tested. The final stage will be the development of smart fertigation and pesticide system which will enable the analysis of psychochemical composition of soil through NPK (nitrogen, phosphorus, and potassium), heavy metal and toxicity tests. The analysis will include mechanical, chemical, and material testing to ensure that the fertilizer samples are nutrient-dense and suitable for use as green durian fertilizer. Thus, this paper presents the first stages toward the development of the smart durian orchard project. At this stage, the outcome of land clearing and preparation for the irrigation project using RGB and thermal imagery data from various drones are presented.

\section{Methodology}

A five-acre smart durian orchard management project in Alor Gajah, $\left(2.341^{\circ} \mathrm{N}, 102.206^{\circ} \mathrm{E}\right)$, as shown in Figure 2 is part of a smart farming program coordinated by the Robotics and Industrial Automation Research Group, Universiti Teknikal Malaysia Melaka. The flights are carried out by using DJI Phantom 3 Pro, DJI Spark and Parrot Bebop Thermal [20-22]. The overall workflow for the monitoring process consists of a pre-flight software, three drones, and software for image and video post processing. Red-green-blue (RGB) and thermal images are acquired and processed at this stages. The results are combined into a comprehensive data management system for further usage in the Smart Durian Orchard Management Project.

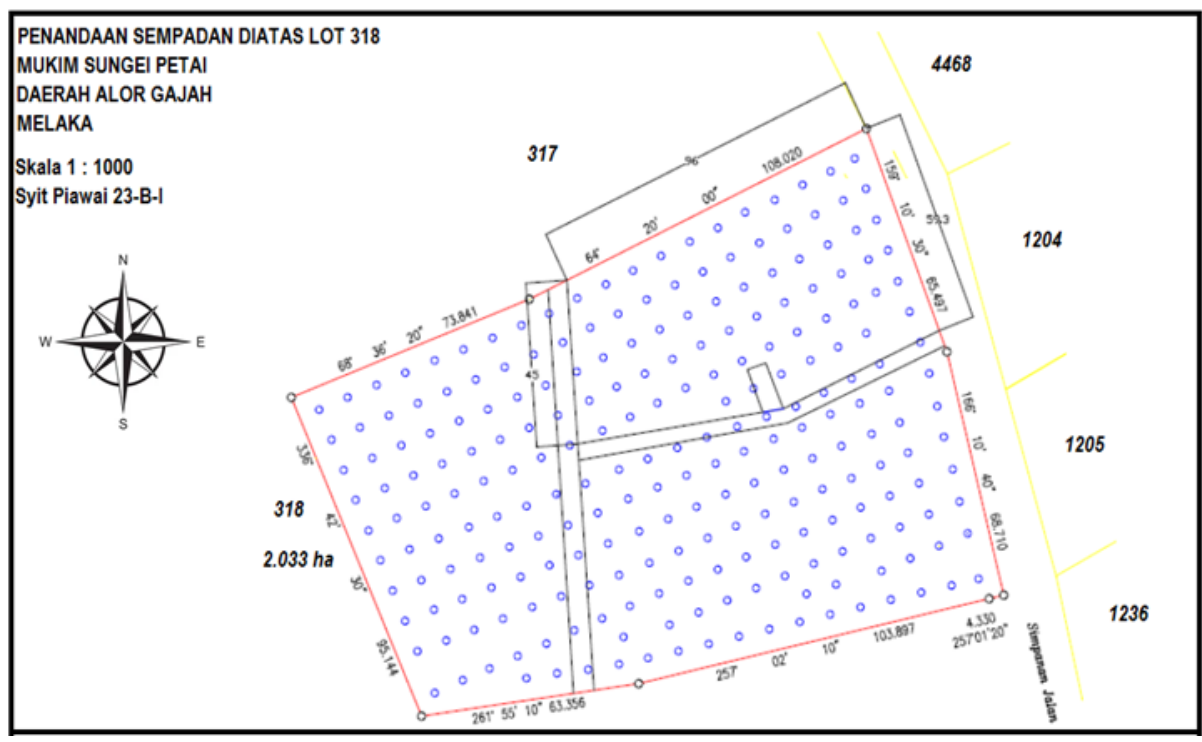

Fig. 2. Location of the project

Table 1 shows the drones' used and the entire process flow in the first stage of the project, which was conducted from September until the end of 2020. 
Table 1

Drones' specification and workflow for the smart monitoring process

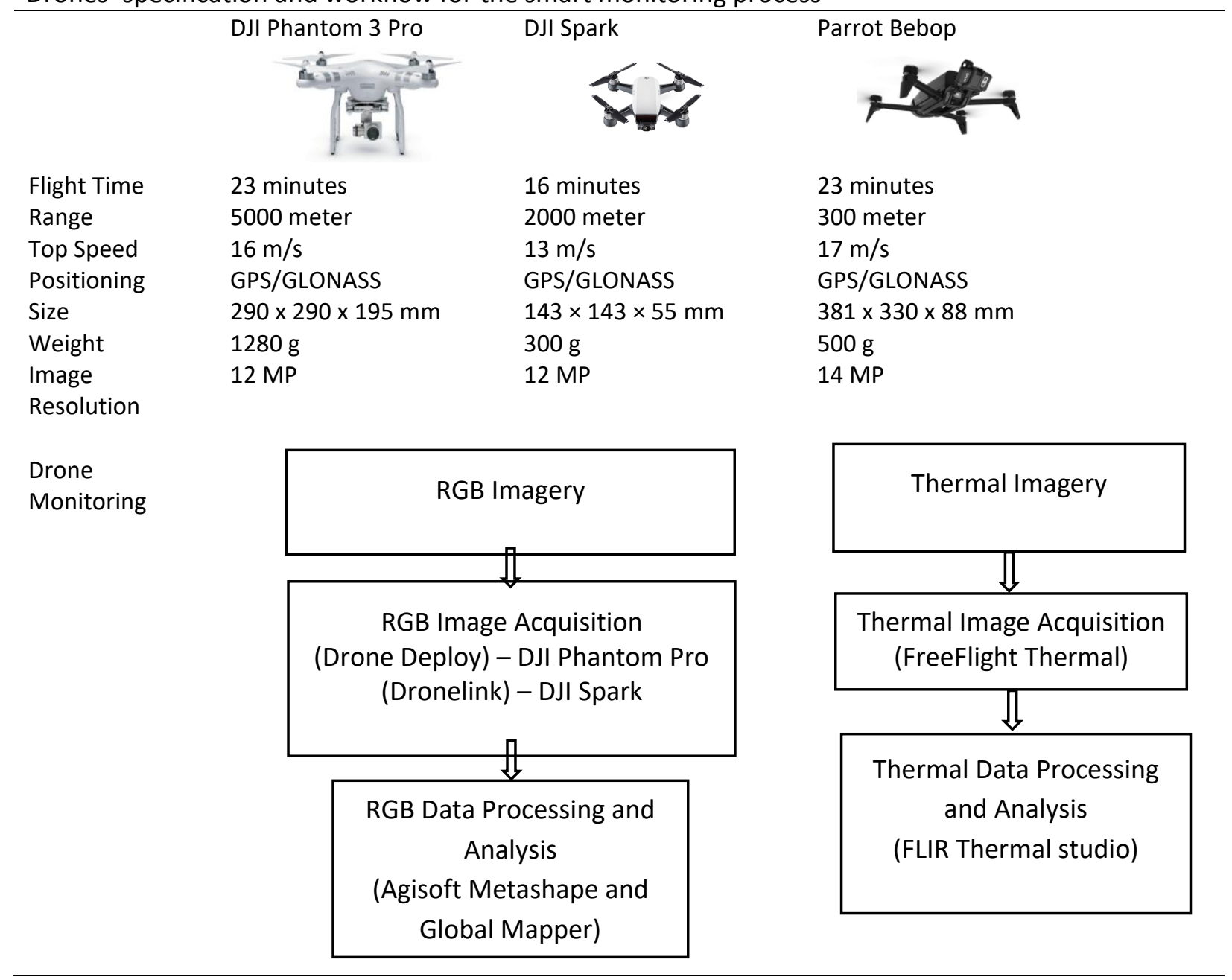

\subsection{RGB Imagery}

Drone Deploy and Dronelink software are used to capture RGB images in the DJI Phantom 3 Pro and DJI Spark, respectively. They are set to fly in an autonomous mode according to a pre-set flight plan, which has been created according to the area of study. The pre-flight software allows the flight plan to include setting a take-off location, a start waypoint, and a landing or home waypoint according to the available flight time. The RGB camera in the DJI Phantom 3 pro has effective pixels of approximate 12.1 megapixels at $94^{\circ}$ angle-of-view lens. The camera system features video recording at up to $4 \mathrm{~K} 30(4096 \times 2160)$ in H.264 and also takes JPEG and DNG RAW photos at $12 \mathrm{MP}$. The Phantom 3 pro drone took 85 geo-tagged photographs in a 13-minute flight, with $80 \%$ image overlap from an altitude of 90 meter. The Spark drone took 77 geo-tagged photographs during a 9minute flight with 80 percent image overlap from an altitude of 50 meter. The RGB images are captured with a spatial resolution of $1.4 \mathrm{~cm}$. The images for the first and second flight plan covering 5 acres of the orchard are shown in Figure 3 and 4. 

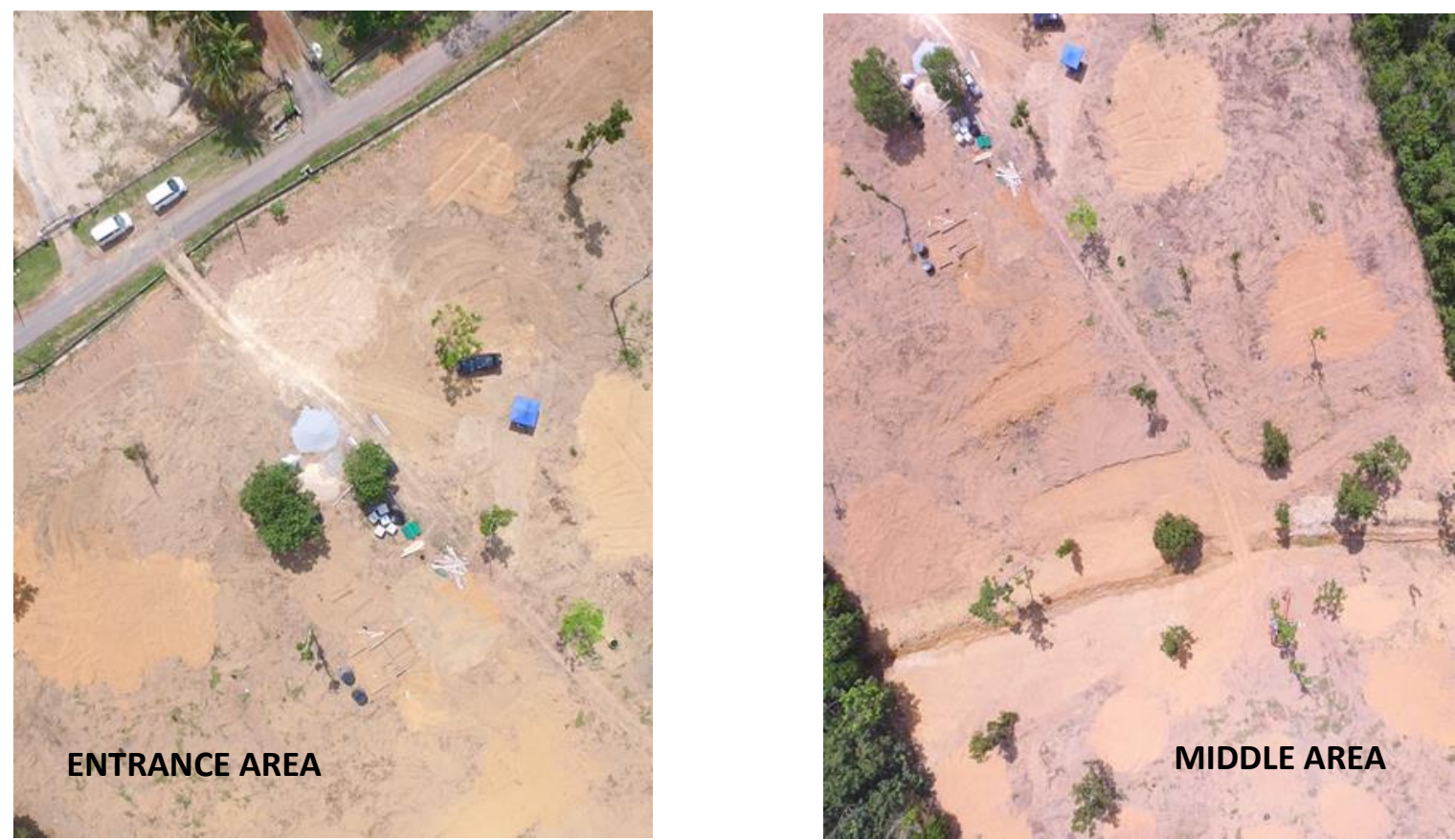

Fig. 3. DJI Phantom 3 Pro images at the entrance and the middle of the orchard. Image taken in $9^{\text {th }}$ September, 2020, 11 a.m. at an altitude of 90 meter
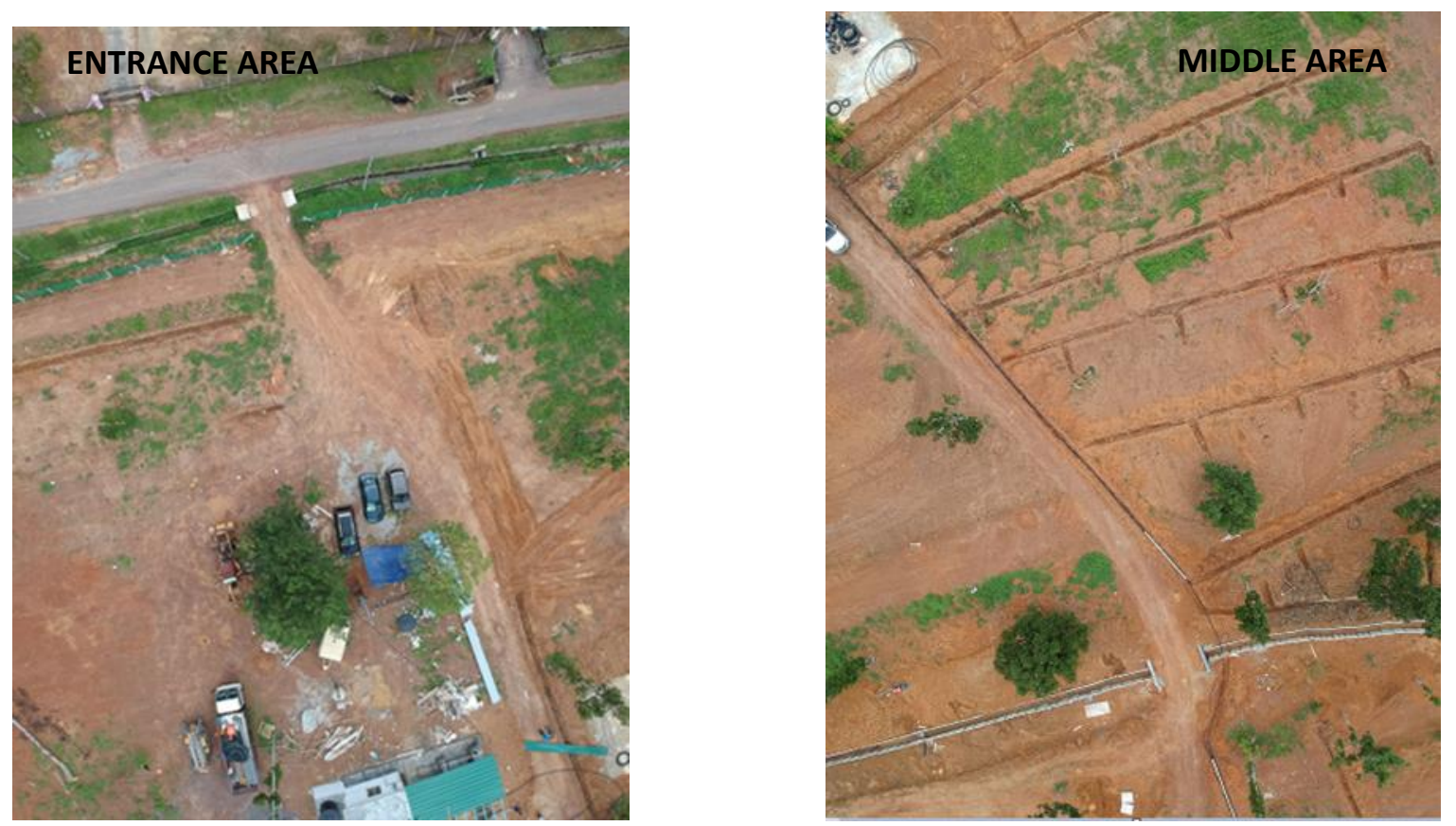

Fig. 4. DJI Spark images at the entrance and the middle of the orchard. Image taken in $15^{\text {th }}$ November, 2020, 3 p.m. at an altitude of 50 meter 

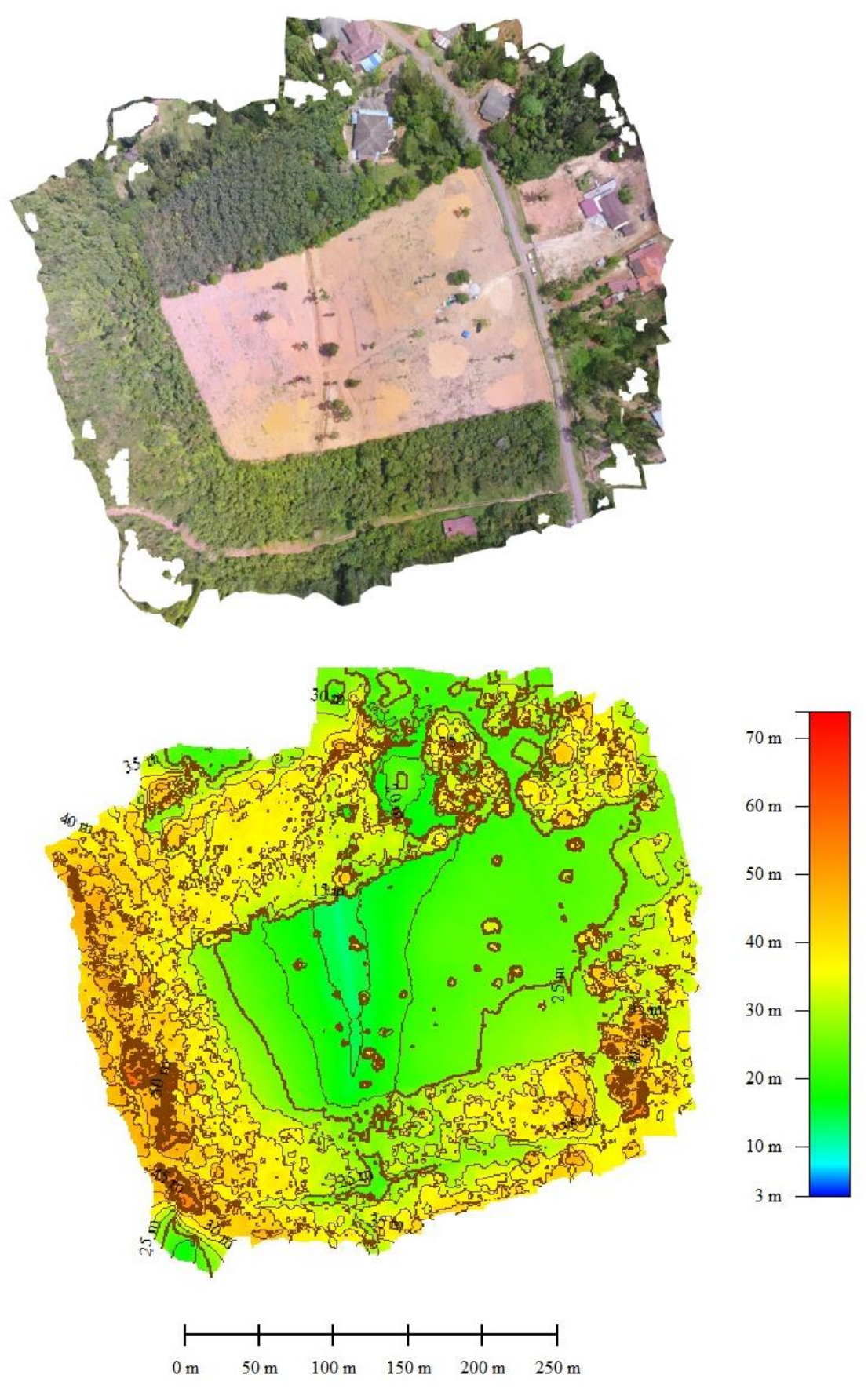

Fig. 5. The digital surface model (DSM) of the orchard 


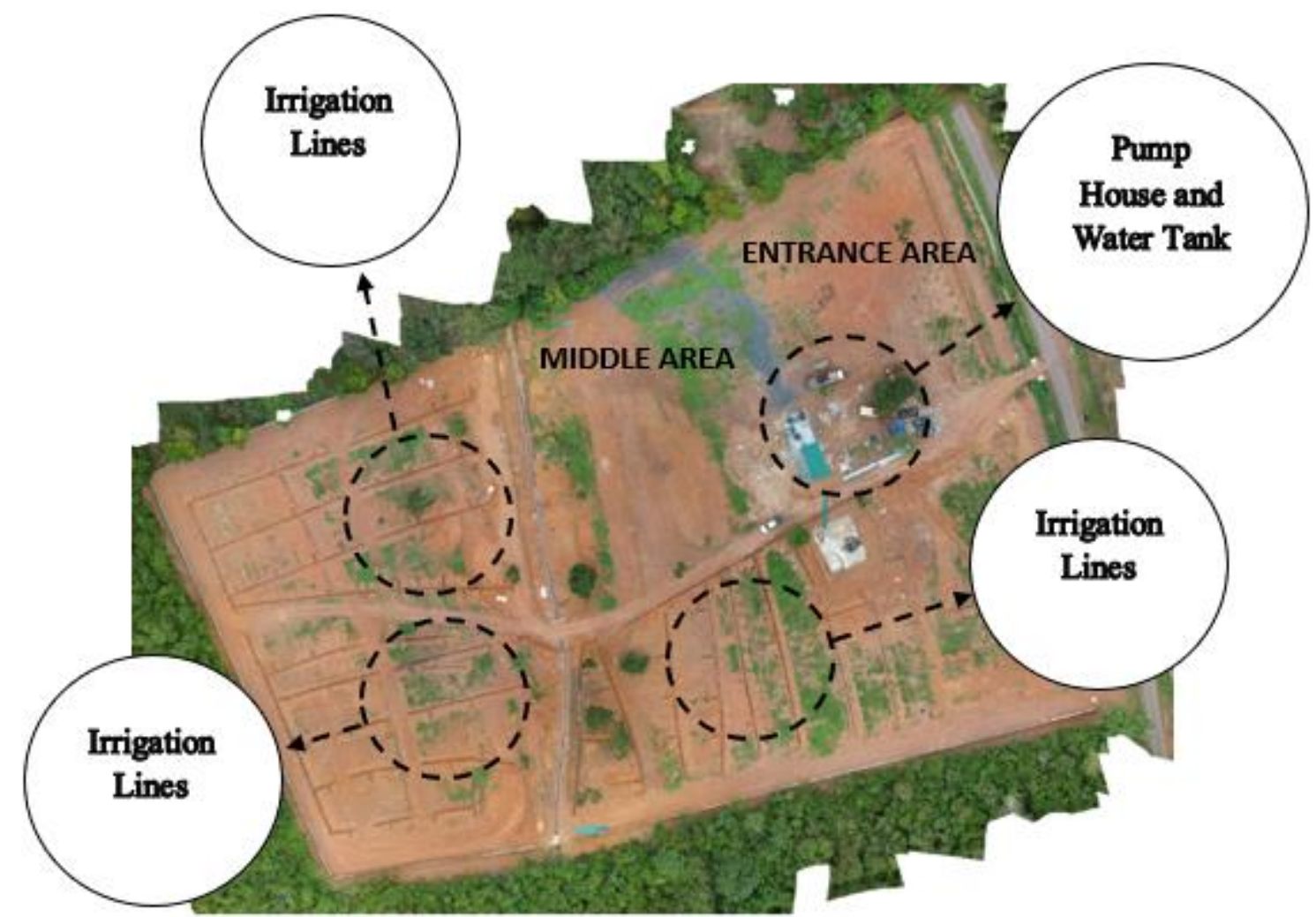

Fig. 6. The 2.5 digital model image taken by DJI Spark in $15^{\text {th }}$ November 2020. Note the view of smart water sprinkler system preparation from above

The photogrammetric image-processing stage starts with the removal of poor-quality RGB images, these included blurry images due to flight motion, those out of focus, images captured outside the study area or duplicate images. The remaining images are then processed in the RGB data processing. In the RGB data processing, structure from motion (SFM) algorithms are used to mosaic the imagery and align it with geo-referenced points using Agisoft Metashape post-processing image software. The software automatically aligns the images and creates point cloud models of the surface for each set of images. It enables the creation and visualization of a dense point cloud model based on estimated camera positions, which can then be combined into a single dense point cloud. For mosaicking the images, the software offers a user-friendly process. Using the photo aligning function, the imagery is added and aligned. The imagery then uses the build dense cloud function to create and visualize a dense point cloud model based on the estimated camera position. It calculates the depth information for each camera so that a single dense point cloud can be created [23-24]. Due to poor texture of some scene elements and noisy or poorly concentrated images, the geometrics of the map are reconstructed using the build mesh function. The images are combined to form a mosaicked orthophoto image, which is then exported as a texture. Finally, the mosaicked orthophoto generates a digital surface model (DSM), which is imported with the orthoimage to generate the 2.5 digital models. Figure 5 and 6 represent the digital surface model (DSM) and the designated area of study, taken from the drones. Further analysis has been conducted by using Global Mapper geographic information system software package, which is used to process elevation layer in generating contours for measuring height differences 


\subsection{Thermal Imagery}

The Bebop drone has been used to capture the thermal imagery, using the FLIR-One Pro camera. It is a thermal infrared camera, featuring a thermal sensitivity needed to detect temperature differences down to $70 \mathrm{mK}$. This camera can capture video footage as well as still images, allowing the creation of thermal maps for later temperature analysis. The camera can capture thermal images with a resolution of 19,200 pixels and measure temperatures up to $160^{\circ} \mathrm{C}$. Depending on the mission, the drone could fly between 40 and 150 meters above the ground. The operator can stream and record from both the embedded visual camera system, and the FLIR ONE Pro camera, from the drone. FreeFlight Thermal software has been used in capturing the thermal images.
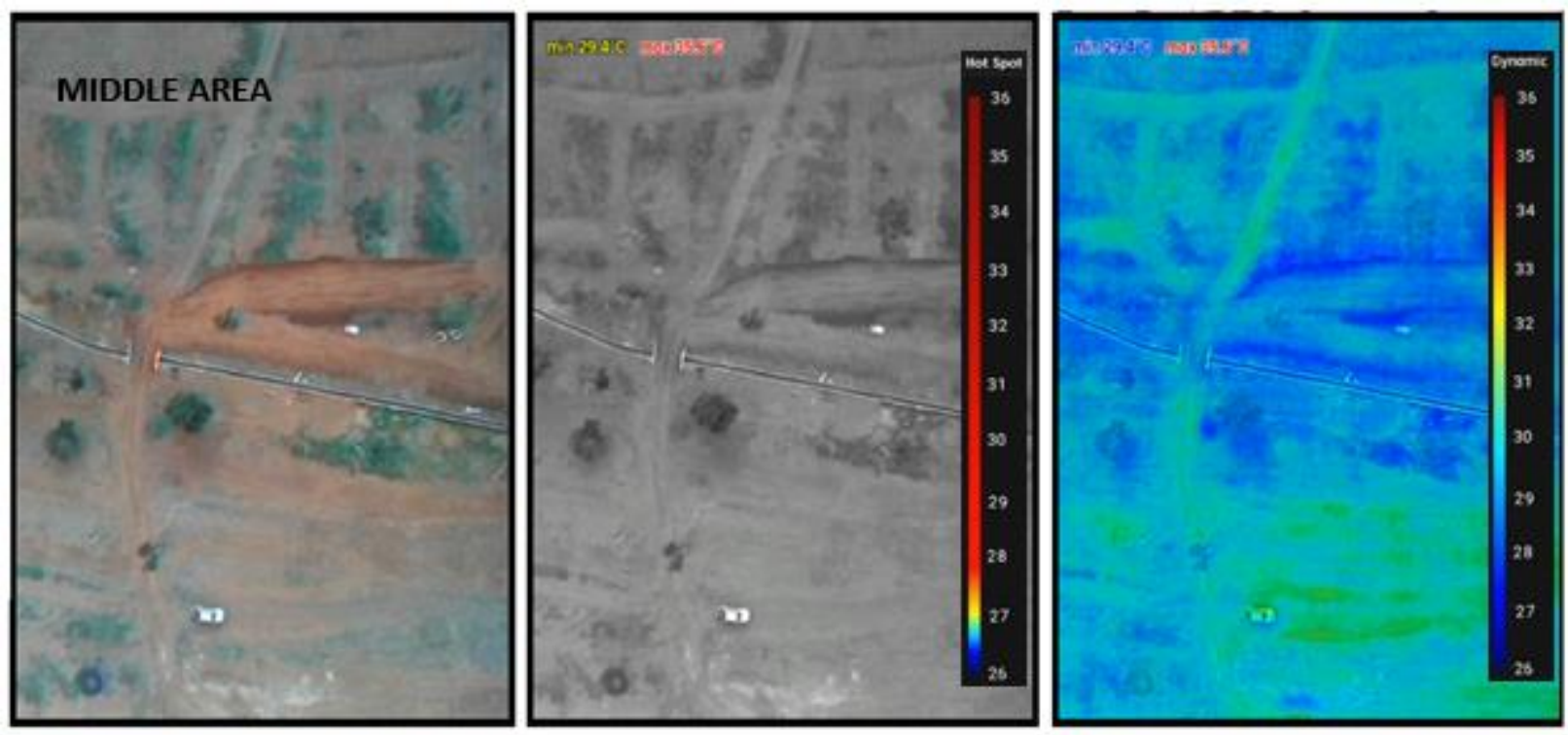

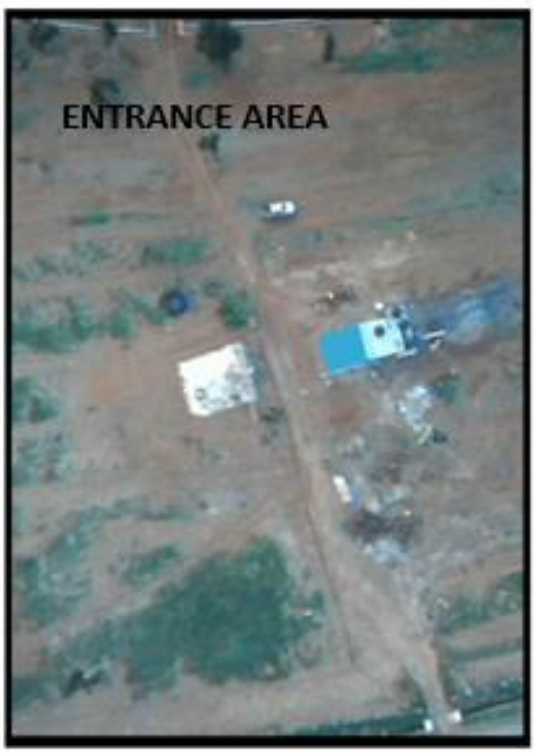

RGB IMAGE

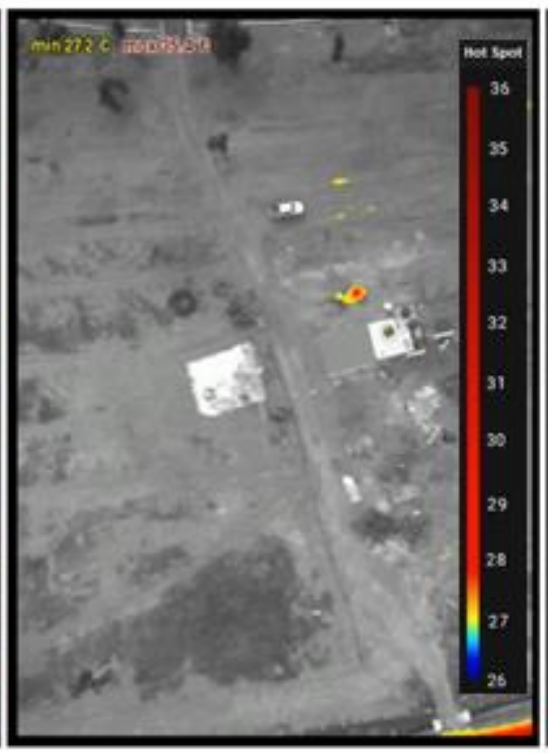

THERMAL IMAGE (HOTSPOT)

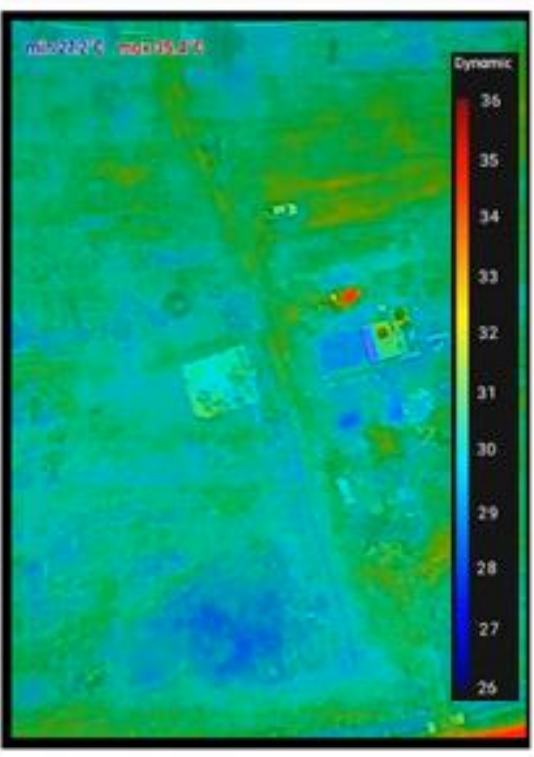

THERMAL IMAGE (DYNAMIC)

Fig. 7. The thermal imagery of the orchard, at the entrance and the middle of the orchard, taken in $8^{\text {th }}$ December,2020, 5 p.m. at an altitude of $110 \mathrm{~m}$ 
The drone also allows the operator to switch between the two cameras. In monitoring the area of study, three different color pallets for thermal imaging are included, and either one can be applied to the recorded thermal footage and exported to a standard video format. The first pallets are the standard pallets, which displays the absolute temperate of everything in the footage, from 10 to $160^{\circ} \mathrm{C}$. The second color pallet is the hotspot pallets, which highlights the hottest temperatures in the video footage. The last color pallet is the dynamic pallet, which automatically rescaling the temperature depending on the minimum and maximum temperature range. Figure 7 shows the thermal imagery from the bebop drone, portraying the orchard from above using the RGB, hotspot and dynamic color pallet.

\section{Results and Discussion}

This section presents the results of the thermal and topographic landscape map at the orchard. The topographic map revealed a detailed and precise graphic representation of natural features such as roads, tracks, houses, contours, elevation, and plants on the durian orchard ground. The general topography of the study area divides the orchard into the region designated as the valley and the hill. Three flights were carried out by various drones in September, November and December, 2020. As flight safety and image resolution can be affected, proper flying procedure has been adopted. To avoid unnecessary accidents, the flight was conducted in good weather and below regulated altitude. The thermal camera's temperature measurements have been calibrated on a regular basis to reduce errors. Simultaneously, the emissivity of the surfaces varies depending on the mineralogy and recorded electromagnetic waveband, which can affect the acquired data. Figure 8 shows the digital elevation model obtained from the mosaicking process. The digital elevation model provides information about the terrain surface of the study area with vertical height range between 3 to 70 meters and horizontal distance range between 0 to 250 meters. The figure identifies these regions based on the color and contour line. The hill has a rise with a slope of around $30^{\circ}$, from the valley. The hilltop stands at a height of $\mathbf{2 7 . 5}$ meters. This condition might not be a favorable aspect for good durian cultivation, as durian usually grows very well on gently sloping land, with 6 to $12^{\circ}$ inclination. The crop prefers deep, well-drained loamy soils not less than 1.5 meters deep, with $\mathrm{pH}$ soil around 5.0 to 6.5. It does not perform well if elevation is higher than 600 to $900 \mathrm{~m}$ above sea level. The durian cannot stand waterlogged conditions, is vulnerable to wind damage during storms and typhoons, and requires protection. Although the valley could provide the needed protection from the wind, the low level area could posed a threat for the waterlogged condition, if not properly monitored. Figure 9 illustrates the valley's cross-section in the study area. The hilly side reaches a maximum height of $\mathbf{2 7 . 5}$ meters and a minimum height of $\mathbf{2 2 . 5}$ meters. It is expected that the nutrients will leach down the slope, due to the high angle of elevation. The valley contains some colluvium soil, while the hill is almost entirely made up of laterite soil with varying depths of lateritic layers. The soil texture is lighter in the hill site, and the nutrient content is similar to the valley site. This is expected because, due to the nature of the landscape, soils on lower sites typically have high moisture and nutrient content. Soil moisture had tremendous effects on flower initiation of durian trees. It is popularly believed that durian trees need a certain level of drought to trigger flowering. Onset of flowering usually occurs during the drought months. However, insufficient water supply for a continuous long period may fail to stimulate the trees to produce more flowers [25-27]. 


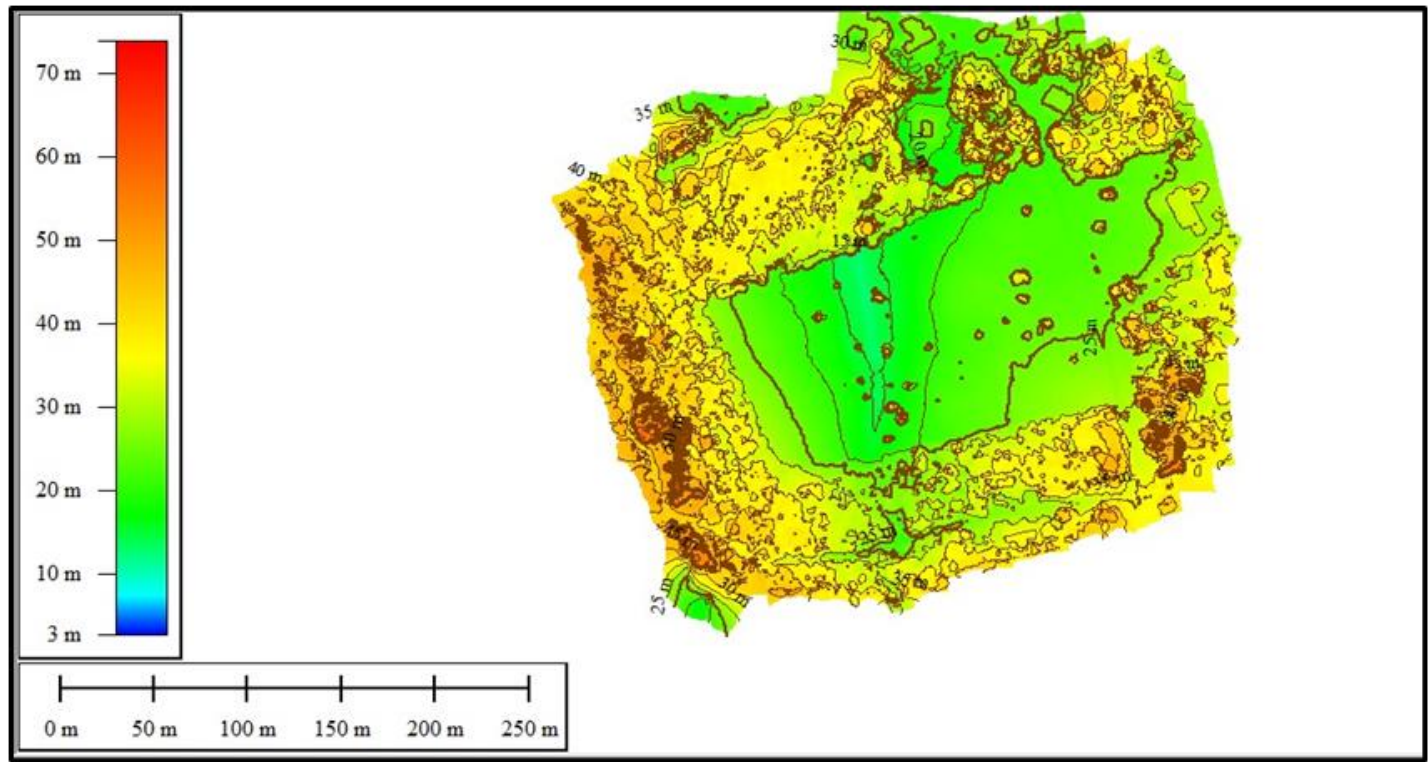

Fig. 8. The possible area with higher concentration of moisture and nutrient at the valley of the orchard

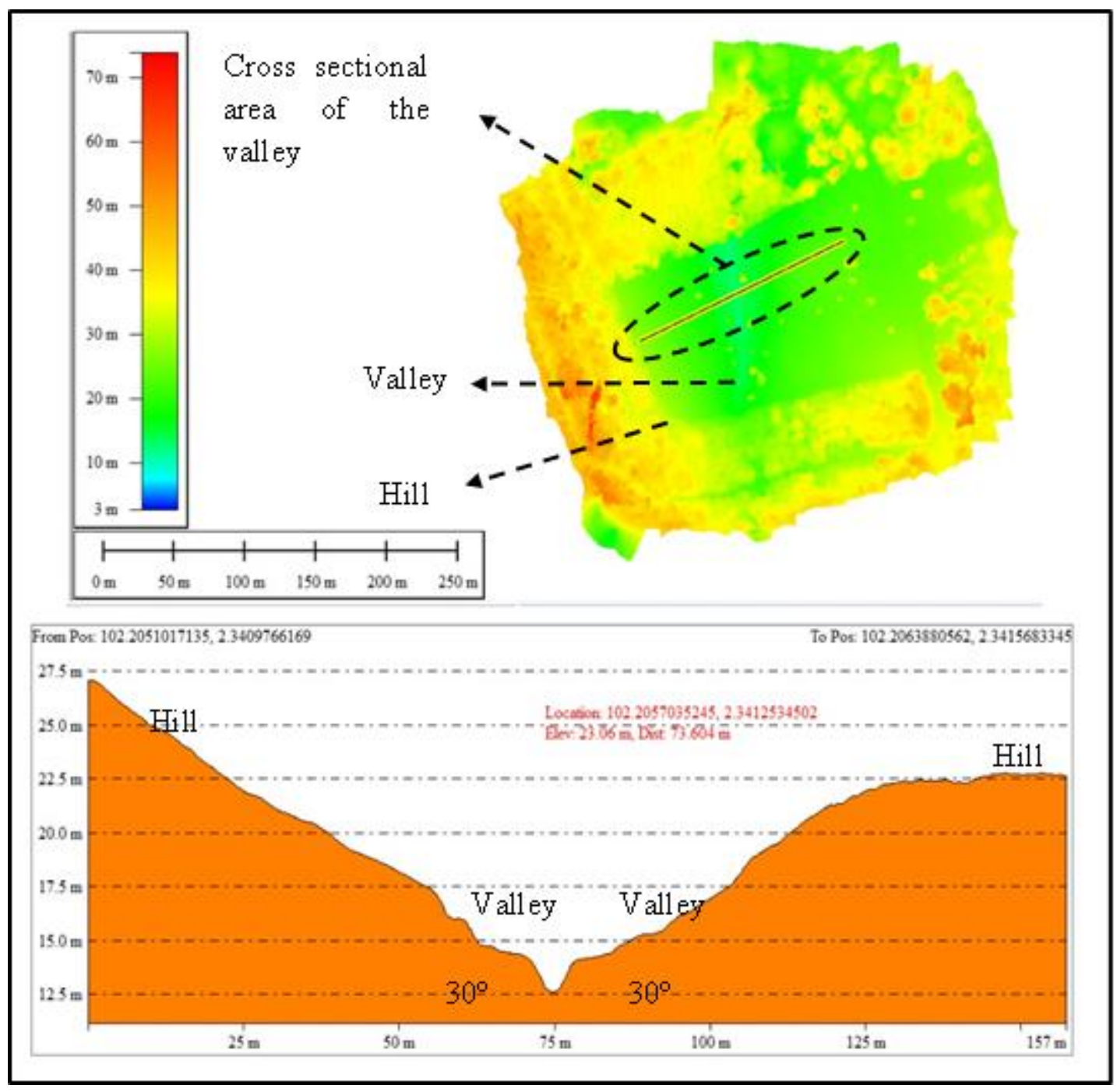

Fig. 9. The cross-section area of study, including the slope of the soil 

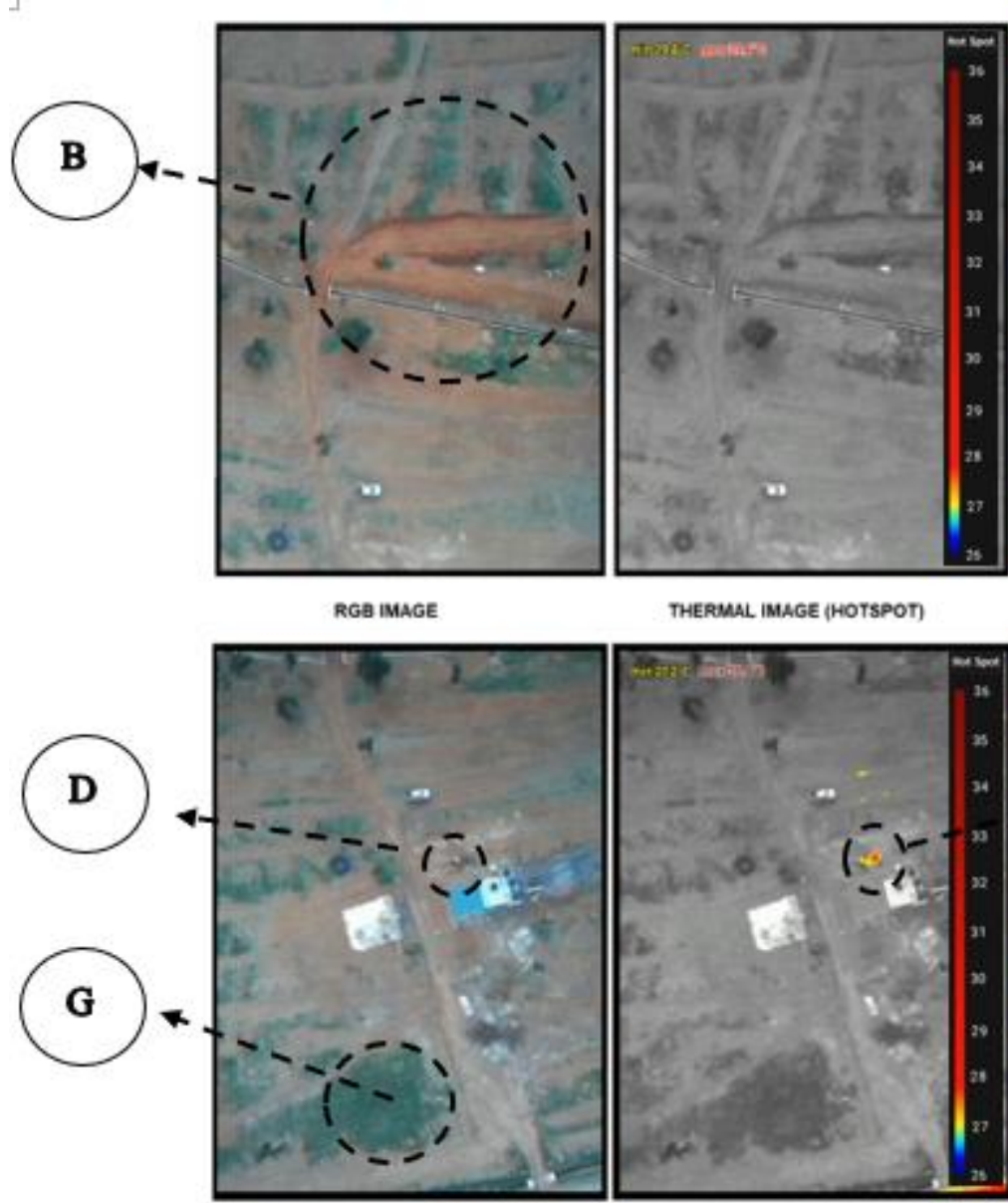

THERMAL IMAGE (HOTSPOT)

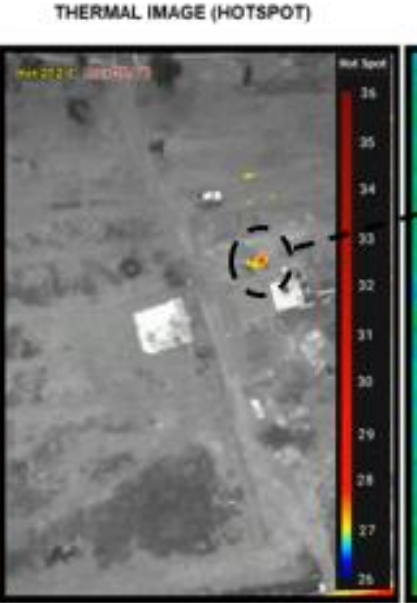

THERMAL MAGE (OMUAMIC)
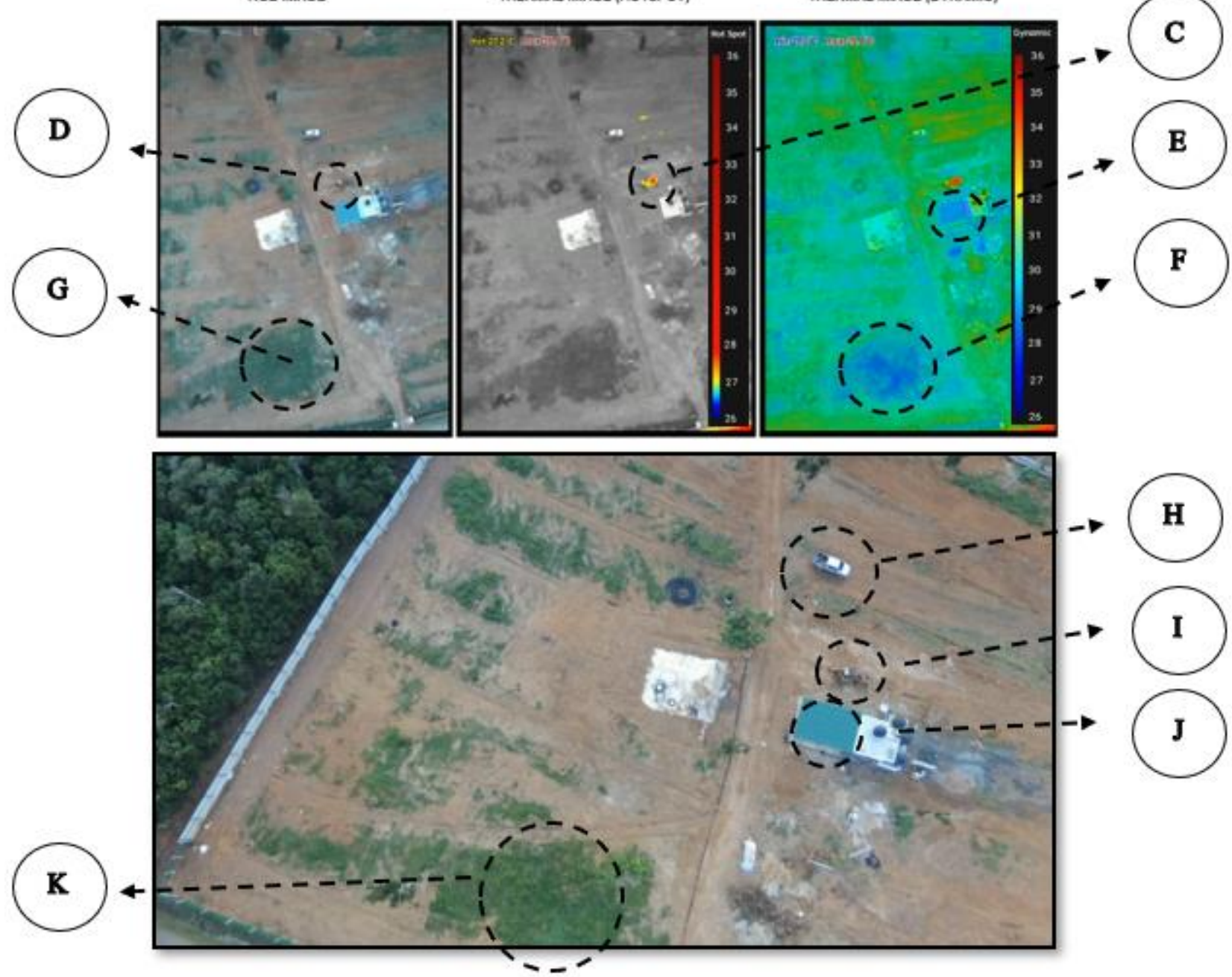

Fig. 10. The analysis of the thermal image

Figure 10 shows the effects of thermal imagery labelled ' $A$ ' through ' $K$.' The research team choose thermal mapping in this area in order to investigate possible of still waters in the soil. In other words, it is important to chart the crop field's wet areas. Young durian trees are very susceptible to drought and high mortality can be avoided with proper irrigation. The mature durian crop requires a dry spell of about 1 to 2 months for flowers to initiate and develop fully. Four weeks after the flowers bloomed, the tree must receive just enough water for proper fruit development. Too much water will cause the tree to bear new leaves at the expense of the fruits. The thermal camera measures absolute 
temperatures of the soil. This will help in identifying moisture and wet area. The region marked with letter ' $A$ ' is the region of the valley recorded with low temperatures value. This proved that the valley has a lower temperature value, as evidenced by the image in the lateritic layers labelled as ' $B$ '. This area suggests that high humidity condition for the soil is possible. At the same time, since the area is at the center and lowest part of the valley, it produces the possibility of having lots of waterlogging, if not properly monitored. The region marked ' $C$ ', on the other hand, suggests a high temperature value. The red dot representing high temperature region is actually an excavator that has just finished preparing the conduit for the orchard sprinkler device. This is clearly visible in the region designated as letter 'D' and 'I'. Simultaneously, the region denoted by ' $E$ ' also designates a low-temperature value, which actually represents the location of a building with a blue metal roofing, as marked by letter ' $J$ '. The letter ' $F$ ', ' $G$ ', and ' $K$ ' indicate low-temperature region in the grassy region on the hilly side of the study area. This suggest that aside from the slope effect, which gathers all the moisture in the valley at one place, the humidity and moisture of the soil can also be affected by the availability of plant and greeneries at the area itself.

\section{Conclusion}

Malaysia's agricultural activity is progressing toward the use of precision agriculture and loT technology as the country moves forward with the adoption of $4^{\text {th }}$ Industrial Revolution. Sustainable agriculture is essential for preserving food production while also protecting the environment from toxic chemicals through better management using latest precision agriculture technology. Drones' technology in agricultural monitoring applications are becoming increasingly popular around the world. Thus, the goal of this research is to use multispectral and thermal images analysis to monitor the durian cultivation process in an orchard at an early stage of production, using various type of drones with different capabilities. The results suggest that the orchard has a steep slope, with an inclination angle of up to $30^{\circ}$, which could affect the crop's yield generation. In general, the location of the soil's moisture and humidity contents throughout the orchard are influenced by the uneven ground surface. Because of the steep angle of elevation, the nutrients are projected to seep down the slope. The hill is almost entirely made up of laterite soil with different depths of lateritic layers, while the valley has some colluvium soil. The hill site's soil texture is lighter, and the nutrient content is similar to that of the valley location. This is to be expected, given that lower-lying soils often have significant moisture and nutrient content due to the nature of the topography. Durian tree flower initiation is greatly influenced by soil moisture. Thus, thermal imaging can be use in detecting the soil moisture distribution that is caused by uneven surface in the area. At the same time, the use of thermal image has provided an insight on the seedling viability throughout the orchard. The soil water status can be predicted at this stage, which has helped the management to plan for smart irrigation project. The images also show that low temperature value can be observed in the grassy and valley area, which support the earlier assumption of nutrient distribution in the area.

\section{Acknowledgement}

The authors wish to thank Universiti Teknikal Malaysia Melaka and Halydin Solutions for their support in the project. 


\section{References}

[1] Cerro, Jaime del, Christyan Cruz Ulloa, Antonio Barrientos, and Jorge de León Rivas. "Unmanned aerial vehicles in agriculture: A survey." Agronomy 11, no. 2 (2021): 203. https://doi.org/10.3390/agronomy11020203

[2] Tampubolon, W., and W. Reinhardt. "UAV DATA PROCESSING FOR LARGE SCALE TOPOGRAPHICAL MAPPING." International Archives of the Photogrammetry, Remote Sensing \& Spatial Information Sciences 45 (2014). https://doi.org/10.5194/isprsarchives-XL-5-565-2014

[3] Honkavaara, Eija, Jere Kaivosoja, Jussi Mäkynen, Ismo Pellikka, Liisa Pesonen, Heikki Saari, Heikki Salo, Teemu Hakala, Lauri Marklelin, and Tomi Rosnell. "Hyperspectral reflectance signatures and point clouds for precision agriculture by light weight UAV imaging system." ISPRS Ann. Photogramm. Remote Sens. Spat. Inf. Sci 7 (2012): 353358. https://doi.org/10.5194/isprsannals-I-7-353-2012

[4] M. Y. Abu Sari. “Large Scale Topographic Map Comparison Using Unmanned Aerial Vehicle (UAV) Imagers and Real Time Kinematic (RTK)". International Journal of Advanced Trends in Computer Science and Engineering 9 (2020). https://doi.org/10.30534/ijatcse/2020/5691.12020

[5] Swain, Kishore C., and Qamar Uz Zaman. "Rice crop monitoring with unmanned helicopter remote sensing images." Remote Sensing of Biomass-Principles and Applications (2012): 254-272. https://doi.org/10.5772/696

[6] Syafiqah, Nor Fatin, Abdul Rashid Shariff, and Nik Norasma Che'Ya. "GIS and UAV Aerial Imaging Applications for Durian Plantation Management." The 40th Asian Conference on Remote Sensing (2019)

[7] Norasma, C. Y. N., MY Abu Sari, M. A. Fadzilah, M. R. Ismail, M. H. Omar, B. Zulkarami, Y. M. M. Hassim, and Z. Tarmidi. "Rice crop monitoring using multirotor UAV and RGB digital camera at early stage of growth." In IOP Conference Series: Earth and Environmental Science, vol. 169, no. 1, p. 012095. IOP Publishing, 2018. https://doi.org/10.1088/1755-1315/169/1/012095

[8] Hovhannisyan, T., P. Efendyan, and M. Vardanyan. "Creation of a digital model of fields with application of DJI phantom 3 drone and the opportunities of its utilization in agriculture." Annals of agrarian science 16, no. 2 (2018): 177-180. https://doi.org/10.1016/i.aasci.2018.03.006

[9] Eisenbeiß, H., E. T. H. Zurich, H. Eisenbeiß, and E. T. H. Zürich. "UAV photogrammetry. Institute of Photogrammetry and Remote Sensing." (2009).

[10] Wahab, Shaliza Hayati A., Nordin Saad, Azali Saudi, and Ali Chekima. "Path Planning for Unmanned Aerial Vehicle (UAV) using Rotated Accelerated Method in Static Outdoor Environment." Journal of Hunan University Natural Sciences 48, no. 2 (2021).

[11] Hatfield, Jerry L., and John H. Prueger. "Value of using different vegetative indices to quantify agricultural crop characteristics at different growth stages under varying management practices." Remote Sensing 2, no. 2 (2010): 562-578. https://doi.org/10.3390/rs2020562

[12] Myneni, Ranga B., Forrest G. Hall, Piers J. Sellers, and Alexander L. Marshak. "The interpretation of spectral vegetation indexes." IEEE Transactions on Geoscience and Remote Sensing 33, no. 2 (1995): $481-486$. https://doi.org/10.1109/36.377948

[13] Carmona, Facundo, Raúl Rivas, and Diana C. Fonnegra. "Vegetation Index to estimate chlorophyll content from multispectral remote sensing data." European Journal of Remote Sensing 48, no. 1 (2015): 319-326. https://doi.org/10.5721/EuJRS20154818

[14] Xue, Jinru, and Baofeng Su. "Significant remote sensing vegetation indices: A review of developments and applications." Journal of sensors 2017 (2017). https://doi.org/10.1155/2017/1353691

[15] Bannari, Abdou, Daniel Morin, F. Bonn, and AjRsr Huete. "A review of vegetation indices." Remote sensing reviews 13, no. 1-2 (1995): 95-120. https://doi.org/10.1080/02757259509532298

[16] Ullah, S. "Thermal plants: characterizing vegetation parameters using mid to thermal infrared hyperspectral remote sensing." PhD Thesis, University of Twente, Enschede (2013).

[17] Liu, Qinhuo, Xingfa Gu, Xiaowen Li, F. Jacob, J. F. Hanocq, M. Friedl, A. H. Strahler, Tao Yu, and Guoliang Tian. "Study on thermal infrared emission directionality over crop canopies with TIR camera imagery." Science in China Series E: Technological Sciences 43, no. 1 (2000): 95-103. https://doi.org/10.1007/BF02916583

[18] Vadivambal, R., and Digvir S. Jayas. "Applications of thermal imaging in agriculture and food industry-a review." Food and bioprocess technology 4, no. 2 (2011): 186-199. https://doi.org/10.1007/s11947-010-0333-5

[19] Hu, Zhenfang, Wenyong Du, and Xiongkui He. "Application of infrared thermography technology for irrigation scheduling of winter wheat." In 2011 International Conference on Multimedia Technology, pp. 494-496. IEEE, 2011..

[20] DJI (2016).DI User Manual Phantom 3 Profesional v.1.8. https://dl.djicdn.com/downloads/phantom 3/Phantom+3+Professional+User+Manual+v1.8 en 20160719.pdf

[21] DJI (2017). https://dl.djicdn.com/downloads/Spark/Spark\%20User\%20Manual\%20V1.6-.pdf 
[22] Parrot (2017). Parrot Bebop-Pro Thermal ${ }^{\mathrm{TM}}$. https://support.parrot.com/files/s3fs-public/firmware/beboppro thermal qsg-en.pdf

[23] Saadatseresht, M., A. H. Hashempour, and M. Hasanlou. "UAV photogrammetry: a practical solution for challenging mapping projects." The International Archives of Photogrammetry, Remote Sensing and Spatial Information Sciences 40, no. 1 (2015): 619. https://doi.org/10.5194/isprsarchives-XL-1-W5-619-2015

[24] Woodget, Amy S., Robbie Austrums, Ian P. Maddock, and Evelyn Habit. "Drones and digital photogrammetry: from classifications to continuums for monitoring river habitat and hydromorphology." Wiley Interdisciplinary Reviews: Water 4, no. 4 (2017): e1222. https://doi.org/10.1002/wat2.1222

[25] Masri, M. "Flowering, fruit set and fruitlet drop of durian (Durio zibethinus Murr.) under different soil moisture regimes." Journal of tropical agriculture and food science 27 (1999): 9-16.

[26] Yaacob, Othman, and Suranant Subhadrabandhu. The production of economic fruits in South-East Asia. Oxford University Press, 1995.

[27] Yaacob, Othman, Mohammad Noor Ismail, and Awaluddin Haji Talib. "Observations on growth and early production of some durian (Durio zibethinus Murr) clones at Universiti Pertanian Malaysia orchard." Pertanika (1978). 